\title{
Early placement breakdown in social work practice placements
}

\section{Catherine Dove ${ }^{1}$ and Caroline Skinner ${ }^{2}$}

Summary: Eighteen social work placement breakdowns have been examined since the advent of the 'new' degree in social work at Kingston University. These constituted 'early' breakdown as opposed to students completing but failing their full 100 day placement. The study spanned the period from 2004 to 2007. The objectives of the study were to:

- Increase understanding to help to retrieve failing placements

- Improve management and support to all those involved

- Develop 'Good Practice Guidelines' and learning materials

- Provide a better social work service to those service users and carers in receipt of a service from social work students at Kingston University

The study identified a complex mix of interrelated factors, resulting in a plethora of strong emotions. A close correlation was noted between the matching of a student experiencing poor health and personal problems with a poor supervisory experience or a team with too high expectations of the student .

Keywords: placement failure; breakdown; problems

1. PracticeLearning Manager

2. Freelance Trainer and Independent Chair, BASocial Work Practice Assessment Panel, School of Social Work, Kingston University

Address for Correspondence: Kingston University and St George's, University of London, Room 111 Kenry House, Kingston University, Kingston Hill, Kingston KT27LB.c.dove@sgul.kingston.ac.uk

Date of publication: 31st March 2011

Acknowledgements: to Hilary Tompsett, Dr Ian Byford and to Professor Ray Jones from Kingston University for their support and advice on this study.

59 J. of Practice Teaching \& Learning 10(1) 2010, pp59-74. DOI: 10.1921/ 146066910X570294. @ wÉb 


\section{Literature review}

\section{Results of previous studies}

There are few studies to be found relating to the breakdown of social work student placements. In 1998 a fairly large study by was carried out at Stirling University (Burgess, Campbell et al 1998; Burgess, Phillips et al, 1998) on placement breakdowns on eight Scottish 'Diploma in Social Work' programme providers. It was found that such events were few but imbued with anxiety and feelings of dread - 'a sensitive and difficult time for all involved' They found that there were many complex and 'inter-related factors contributing to failed placements'. (Burgess, Campbell et al 1998, p.4).

The Burgess study looked at the processes involved and the availability of possible support for all parties involved. Issues of power and discrimination emerged as salient factors in relationships between students and their practice assessors, with there being a real dichotomy or split between the views of assessors and students deemed as having failed a placement.

Many of the students who failed saw it as very 'traumatic' event affecting their lives, careers, incomes and other people close to them. They felt unfairly treated by their assessors but saw their tutors as more 'neutral' and in 'supporting roles' and generally felt dissatisfied by the whole experience.

The Burgess study identified seven main and often inter-connected reasons why placements were unsuccessful:

- The personal circumstances of students (for example health, bereavement, family tragedy)

- A 'personality clash' between the student and the practice teacher or link supervisor

- Travelling distance from student's home to placement

- The placement not providing enough or the right work experience

- Insufficient support for the student

- Inexperience of the practice teacher

- The student's academic or writing ability

60 J. of Practice Teaching \& Learning 10(1) 2010, pp59-74. DOI: 10.1921/ 146066910X570294. @ w\&b 


\section{Feelings of those involved in unsuccessful placements}

Strong feelings amongst all parties were noticed as a feature of unsuccessful or uncompleted placements (Burgess 1998). Studies into the emotions evoked on practice or 'field' placements (Barlow \& Hall, 2007; Baum, 2007) discuss the powerful feelings projected from the service users onto student social workers, as well as examining relationships between students and their supervisors. Barlow \& Hall (2007) conducted a Canadian study into 35 students and their field instructors to try and understand how emotionally distressing events on placement were managed regarding the impact of service user distress on students. The authors noticed feelings of vulnerability when students were faced with 'situations that reminded them of their own past, personal pain or when an encounter with a client called for a re-examination of personal beliefs and values'. (Barlow \& Hall, 2007, p.403).

Perhaps what was significant in this study was that it was the field supervisors who were most concerned about students' past trauma 'as an influence on professional responses and creating stress', and its impact on their work, whereas only three of the students cited personal issues as sources of tension at work. This finding echoes the Burgess study (1998) whereby students and their assessors were not usually found to be in agreement about the assessment when a placement failed.

Baum (2007) in a similar study into field placements in Israel sees the supervision of students as vital to social work practice ensuring that 'self awareness and enhancement of skills '(Baum 2007, p.1095) can be taught on field placements. She concluded that field supervisors needed more support on coping with relationships with their students, and more training around the termination / endings of placements.

\section{Placement roles and relationships}

As stated above (Burgess $1998 \mathrm{ii)}$ found that the students who failed placements felt very unhappy and often cited a lack of choice of placement as well as relationships with their assessors as problems leading to failure. The practice teachers cited that students' poor practice included:

61 J. of Practice Teaching \& Learning 10(1) 2010, pp59-74. DOI: 10.1921/ 146066910X570294. @ wEbb 
- Poor communication and inter-personal skills

- A lack of basic ability

- Poor understanding of the social work role

- An absence of professional boundaries

- A lack of motivation $\&$ unwillingness to learn

Many of the tutors in the Burgess study saw the practice teachers as a 'significant factor' in failed placements, displaying unclear communication skills, poor assessment ability and showing unprofessional conduct. Similarly poor supervisory skills in link supervisors, and poor communication with the practice teachers were seen as significant factors in failed placements.

Burgess also notes the lack of experience of link / work based supervisors as a contributory factor in failing placements. Henderson (2010) notes the change in the increased use of off site practice teachers and work based supervisors since the advent of the new degree at Kingston University, citing over half of all practice placements currently utilise this model of practice learning. Her research examines the role of the work-based supervisor, viewing them as the 'neglected partner' with a power imbalance inherent between work supervisors and practice teachers. She notes the fact that four people are now often involved in the practice learning partnership (the student, the practice teacher, the work based supervisor and tutor), and that this can only complicate the placement for students who have to negotiate a four way relationship between partners of perhaps very differing abilities and knowledge.

Similarly, Maidment sees field education in New Zealand as a 'complex enterprise' (Maidment 1999, p.55) with the tensions inherent in social work i.e. the struggle for occupational control and identity manifesting itself in field relationships. She also looks at previous studies in the UK and sees similar factors to Burgess (1998) as influential on placements:

- The personal attributes and skills of the field educator

- Gender match of assessor and student (the Burgess study (1998) noted more male students failed proportionately with female practice teachers)

- The quality of the learning experience

- The quality of supervision and relevance of learning

- The knowledge and enthusiasm of the field educator

62 J. of Practice Teaching \& Learning 10(1) 2010, pp59-74. DOI: 10.1921/ 146066910X570294. @ w\&b 
Unfortunately many of these studies do not analyse what went well in successful placements so the only account presented is associated failure. It could be the case that many students do well and survive the negative aspects of many placements, so it could be concluded along with Burgess (1998) that multiple factors are at play which impact negatively on placements where there is an unsuccessful outcome.

Lastly, the studies explored also suggest that practice educators may need more support and ongoing training, particularly in respect of how to manage difficult or failing placements.

\section{Methods}

Two methods were used to gather information on the early termination of placements at Kingston University.

Firstly, information was gathered from an analysis of the Practice Assessment Panels' documentation over the last three years. These documents reflected the discussions and the views held by the multi-agency Panel, which included service users and carers as well as experienced practice teachers, university tutors and agency representatives. The documents included full reports completed on the student by practice teachers, on site supervisors, the students themselves and sometimes reports from tutors. These documents are ordinarily available to the two researchers as part of their day-to-day work within the university.

Secondly, the researchers also interviewed the university tutors who had experience of a student in their Learning Team experiencing a placement breakdown. The interviews were carried out by both researchers using a semi-structured format to allow tutors the opportunity to voice their opinions on what happened in each placement breakdown. Tutors were selected for this task as it was felt that they might hold a slightly more objective viewpoint in comparison with the practice assessors and students directly involved and immersed in the emotional tensions created by early placement breakdown. The authors secured permission from the Head of School and sought advice for the study from the Faculty Ethics Committee at Kingston to complete this study.

63 J. of Practice Teaching \& Learning 10(1) 2010, pp59-74. DOI: 10.1921/ 146066910X570294. @ wEbb 


\section{Key themes in the early endings of placements}

\section{Health issues}

The student's health was an issue in twelve of the eighteen placements. Pregnancy was cited in two cases and linked to this were some problematic health issues coupled with difficult personal circumstances. Other students had documented serious health problems. One placement was ended after 35 days due to the serious ill-health of the student. Stress, anxiety and mental health issues were cited as contributory factors in many of the early placement endings. Tutors often confirmed that stress and anxiety had impacted on students already struggling with health issues and / or difficult personal issues.

One student said she felt 'tearful' and reported feeling low and anxious. Other students suffering from anxiety had time out 'off sick' from the placement and several talked of feeling emotionally distant or 'cut off' from their team, showing how feelings of ill health increased relationship problems on placement. In some cases these feelings escalated to more serious feelings of depression about what colleagues on the team were thinking. These feelings of alienation and feeling overwhelmed led to several students feeling unable to engage with activities and work on placement, more often and perhaps significantly on mental health placements. A student on a children's team also stated she felt depressed and it was felt by the student and her assessors that the work possibly triggered unresolved memories for her.

One student reported that other members of the team were talking about him in a derogatory way - something for which there was no evidence. He began to withdraw emotionally from other members of the team, including his work-based supervisor. He chose to cut himself off from the team, preferring to work in a small, separate office in self-enforced isolation. He continued to feel 'low' and anxious and declared that he was worried he may 'break down', because of concerns about his placement, his studies, his family and other work responsibilities. A significant number of students' emotional distress and mental health issues led to communication problems between the student and the practice assessment team, often with the tutor being notified too late of a serious threat of imminent placement breakdown.

One question, to emerge within the 'Health' category was whether

64 J. of Practice Teaching \& Learning 10(1) 2010, pp59-74. DOI: 10.1921/ 146066910X570294. @ w\&b 
anxieties over placements exacerbated already-existing health conditions or whether anxiety over the anticipated ending of placements triggered new health problems? The stress and anxiety issues of students were frequently commented on in the end-of-placement reports by assessors, but there is often no indication as to whether these symptoms were already present or whether they emerged as a result of the stress of a placement termination. When asked, the tutors varied in their opinions but most students claimed their mental distress was due to the placement and related anxieties. Burgess (1998) also noted the presence of mental ill health in failed placements and recommended further research into this concern.

Not all of the health issues concerned the student. In one case, the practice teacher was unwell from the start of the placement and often worked from home. The poor health of the practice teacher was a significant issue as it triggered a difficult-to-manage working relationship that eventually became untenable. Health of either involved party was therefore a major factor in many of the early placement breakdowns.

\section{Personal issues}

Personal issues played a major factor in the termination of ten out of the total of the eighteen placements. Although personal issues have been looked at as a separate issue from health-related problems - in many instances, they overlapped.

For example one placement was terminated after a few days. The student disclosed that the work was raising memories of her own childhood experiences. The helpful and frank three-way meeting at which the placement was terminated noted that continuing with the placement would only have added to the student's distress.

Another placement was terminated after 90 days, when the student herself made the decision to leave. The practice teacher's report notes that the student's personal issues impacted, 'significantly on her ability to demonstrate her true potential on placement' and that she 'struggled with many personal and family problems during placement.'

Personal, family and caring circumstances were stated as a stress to many students. Over half of these students studied were struggling as lone parents, caring for sick relatives, or supporting family in

65 J. of Practice Teaching \& Learning 10(1) 2010, pp59-74. DOI: 10.1921/ 146066910X570294. @ wËb 
other countries. Travel issues (such as the distance from home to the placement) and financial issues also seriously impacted on some students' ability to cope. Several students were working long hours in paid employment which added to their stress and workload overall. This distraction and the preoccupation of students with problems in other aspects of their lives led practice teachers to question their motivation to complete placements, or even do social work. As the personal problems continued to impinge on their practice, several students were encouraged by practice teachers and tutors to seek counselling support before continuing with the commitment of placements.

It would appear that a key factor in the early ending of a placement is whether the student has either physical or mental health problems and/ or whether they are experiencing personal difficulties in their personal life which prevents them focusing fully on their placement.

\section{Supervisory and support issues}

The third common key theme was the student's access to support and supervision which was a factor in nine of the failed placements. These students expressed unhappiness with their supervisors, or complained of a lack of structured and positive support from either the practice assessor, the work based supervisor or both.

One practice teacher had health problems and had been given leave to work at home for much of the time. This meant the student was without a supervisor for long periods. It was felt that issues about the availability of the practice teacher were crucial to the breakdown of this placement as the team offered no further support. The question of frequency of supervision was raised and there were counter-allegations as to the frequency and recording of supervision. When supervision did occur, the student reported that there was no encouragement to discuss issues and stated that only the practice teacher talked.

Another student argued that her placement did not provide adequate learning opportunities and that she did not receive regular supervision tutorials from her practice teacher. Some students were very critical of supervisory practices on placement. Students complained of practice teachers being negative towards them, of non-availability, of irregular supervision, and poor feedback from their assessors. One student accused the work-based supervisor of not showing her 'how to do an

66 J. of Practice Teaching \& Learning 10(1) 2010, pp59-74. DOI: 10.1921/ 146066910X570294. @ w\&b 
assessment'. She said she received 'no positive feedback only criticisms' and blamed the supervisory relationship on her resulting health problems as 'the constant criticism he gave me resulted in me feeling depressed and led to my high blood pressure'.

Others were not happy at the lack of support throughout and said they were not given notice about the possibility of a termination of placement. One student stated that there was no three-way meeting with the tutor prior to termination and that she was not provided with an action plan to improve her practice. Another said that the practice teacher came to the three-way meeting with the tutor having already been advised by the Senior Social Worker that the placement was to be terminated. A few complained they were not given opportunities to improve their work, and were not given encouragement or positive feedback at all.

Another student had had a change of work-based supervisor when the original work-based supervisor (manager) left the agency. This change in the working relationship was disruptive for the student. Before the work-based supervisor left a three-way meeting took place, which both the practice teacher and the work-based supervisor felt had gone well, while the student felt her needs had been overlooked. She felt they were 'uniting' against her and that nobody was supporting her.

One final placement student claimed that she was made to feel 'unwelcome' by the team, because of the experience of the team with a former failed placement. The off-site practice teacher was said to be very supportive but the student stated that support and supervision from the work-based supervisor had been 'inadequate and purely negative.' It would seem that the negative experiences of past practice relationships had resulted in a breakdown of current practice relationships.

\section{Relationships}

Relationship issues were considered a factor in ten of the failed placements with poor relationships invariably overlapping with reports of negative supervisory relationships. A tutor in one case noted that there was 'no effective working relationship or trust between the practice teacher, work-based supervisor and student,' and that there were 'different perspectives on how things were going'.

Some students were less than honest about their whereabouts and

67 J. of Practice Teaching \& Learning 10(1) 2010, pp59-74. DOI: 10.1921/ 146066910X570294. @ wE-b 
this created tensions in practice relationships. One student explained that the power imbalance of being assessed made her unable to explain honestly how she was feeling or where she was, and this exacerbated already strained relationships. One student was reported to be 'defensive, aggressive and intimidating' to a manager, although there were also issues about the clarity of messages that the student was receiving from her assessors. One report noted that the relationship between the practice teacher and student had 'clearly broken down' with the practice teacher declaring that the student had not learnt from 'earlier mistakes'.

Some students with health and/ or personal problems said that they felt unsupported by their assessors. Different perspectives of the work-based supervisor, practice teacher and students showed that their three way relationship was under strain. One work-based supervisor noted that the student 'showed little enthusiasm' and 'found it difficult to reflect and evaluate her work', whilst the student cited 'irregularity in her assessment process'. Another student claimed her assessor was 'unsupportive' and 'unfair'. These very different perspectives led to an irrevocable breakdown in the relationships within some placements.

One student with anxiety and stress issues claimed she felt unsupported, and did not like the team whereas the assessors did not feel the student had shared information, showing the relationship was not one of trust and openness. At one termination meeting the team manager commented that everyone concerned seemed to have difficulty expressing themselves openly and that the case highlighted the importance of sharing difficulties, discussing them openly and maintaining honest relationships.

\section{Immaturity, inexperience, possible lack of commitment of student}

A lack of commitment and an inability to understand the responsibilities of being a social work student were apparent in nine of the failed placements.

The Mid-Point review report of one student stated the student needed to 'demonstrate a more consistent understanding and commitment to social work practice'. The practice teacher thought the student struggled with 'a holistic understanding of social work practice and failed to demonstrate an understanding of values and ethics.' It was also felt

68 J. of Practice Teaching \& Learning 10(1) 2010, pp59-74. DOI: 10.1921/ 146066910X570294. @ w\&b 
Early placement breakdown in social work practice placements

that she had difficulty in engaging with the diversity of service users and did not fully appreciate her own duties and responsibilities as a student social worker.

This was a theme often referred to by practice teachers as 'unprofessional' behaviour on placement, which raised feelings of disappointment, loss of expectation and even anger in assessors. Students were seen as having a 'lack of integrity and difficulty working with service users.' Some of the students had unexplained absences raised the question of their commitment to social work values. One work-based supervisor noted, 'this student's attainment has been varied - she quickly became bored and disinterested with the areas she found more challenging. She has lost motivation to succeed - hampered by personal problems'.

Another practice teacher noted a 'lack of commitment', a lack of selfawareness and 'limited life experience' due to age and circumstances. She noted that the student was not 'picking up indicators of underlying issues' of service users and was unable to meet agency deadlines. These examples denote a lack of professional behaviour in the workplace and many assessors felt students with problems at home were not always able to distance themselves from their home-life and were unable to develop and act in a professional, responsible manner towards their work. Many practice teachers said that students did not always follow instructions, had issues with 'authority' and did not complete agreed plans. This, in turn, led to poor assessments and one assessor commented that she did not get a 'true picture of the client's view of her needs.' Overall this student was not seen as taking responsibility for her mistakes and 'was not able to act as an accountable professional'.

It is significant that in discussion with university tutors, two out of three tutors interviewed regarding students where lack of commitment was an issue, stated that they had observed this approach during first year tutorial meetings. One tutor commented that she was, "concerned about [the student's] level of commitment - she was not that engaged. She missed Learning Teams, and had no passion or enthusiasm about social work'. Further comments included, 'going through the motions' and a 'lack of commitment rather than lack of confidence' were seen as an issue.

69 J. of Practice Teaching \& Learning 10(1) 2010, pp59-74. DOI: 10.1921/ 146066910X570294. @ wËb 


\section{Secondary themes from the research}

The issues detailed below contributed to the early ending of some placements but were not seen as the main reasons for termination.

\section{The Student's own perceived ability to learn and own views on competence}

Six students highlighted this themselves as an issue for them on placement. One acknowledged that she did not fully understand her duties and responsibilities on placement. She also acknowledged that she did not understand the importance of social work values and ethics. This student found working with a range of service users difficult and she struggled with a holistic understanding of social work practice.

Another student said that she struggled with practical tasks, such as interviewing and assessment and stated that she lacked confidence. Another recognised that she had difficulties in providing material and linking theory to practice. Despite being on placement for ninety days, she failed to provide the practice teacher with work on time and she was unable to produce any competent written reflective pieces of work.

\section{The practice teachers' perception of the students' ability to learn}

Four practice teachers felt that the students' practice was not sufficiently competent for a final placement or there were also issues relating to students' report-writing skills, including inability to select and organize information. These practice teachers stated that students were not able to understand the role of the social worker within the setting and could not grasp the nature of the work. Other assessors expressed a view that students had not learned from their previous placement experiences and had concerns over the students' ability to work with service users.

J. of Practice Teaching \& Learning 10(1) 2010, pp59-74. DOI: 10.1921/ 146066910X570294. @ w\&b 


\section{Lack of work provided to practice teachers}

Documentation relating to eight students noted the lack of written work provided by the student to the practice teacher. These students failed to provide both portfolio-related work and agency-related work to assessors.

\section{Placement suitability / poor learning opportunities provided}

This is more difficult to comment on, as other students may well have found the same placement settings worthwhile and fulfilling. However it is worth commenting that placement suitability did seem to be a contributing factor to the placement breakdown in five examples, which is just under a third of placements - a significant number.

\section{Expectations of team/disparity between students and assessors}

Some students claimed that teams were unsupportive and expected too much of them. The Practice Assessment Panel noted one practice teacher and her team had too 'high expectations' of the student in a very busy pressurised statutory childcare team, whereby the student was almost expected to be performing at the level of a qualified social worker.

\section{Summary}

To conclude the five key factors found that appeared to contribute to the majority of early ending of placements were:

- Health issues of the student or practice teacher

- Personal issues of the student

- Support or supervisory issues

- Relationship issues

- Issues relating to immaturity, lack of commitment and/or inexperience of the student

71 J. of Practice Teaching \& Learning 10(1) 2010, pp59-74. DOI: 10.1921/ 146066910X570294. @ wEbb 
Overall these five themes were all present together, in at least half of the placements examined.

Two of these - health problems and personal issues, relate primarily to the circumstances of the individual student. It can be seen that, although they are separate issues, they invariably overlap and both are often present. It would appear that a key factor in the early ending of a placement is when a student has either physical or mental health problems and/or difficulties in their personal life. This combination was highly detrimental to students being able to focus on their placement, and seemed to create a plethora of communication problems on placement.

The two key themes, support and supervision and relationship issues, involve all parties taking part in the practice learning opportunity. They include students receiving inappropriate or poor support and supervision, and a picture of incompetent management of the assessment and learning experience as provided by the assessment team. These issues often manifested themselves in poor communication between all involved parties.

The last key common theme often cited as 'a lack of a professional approach' refers to the standards of the student's practice and behaviour on placement. This was more difficult to define and emerged as a lack of understanding by the student of the role and responsibilities of a social worker. It included a lack of integrity and honesty, inability to relate theory to practice, a lack of commitment and an immaturity that resulted in students being unable to accept their responsibilities on placement. These attributes were invariably observed or known about, by University staff, prior to the commencement of placement.

Students need to be prepared and ready to begin their practice learning. This research shows that preparedness must include good physical stamina and robust mental health, the ability to manage one's personal life and a maturity and understanding of the requirements and responsibilities of social work.

The findings from this small study into the early breakdown of social work placements lead to a number of recommendations for students, tutors and practice supervisors.

2 J. of Practice Teaching \& Learning 10(1) 2010, pp59-74. DOI: 10.1921/ 146066910X570294. @ w\&b 


\section{Recommendations}

1. University staff could make more judicious use of the University's Occupational Health services to assist them in their task in the assessment of student ill health and its impact on placements.

2. Students should be encouraged, and if necessary required to defer if their personal difficulties and or health are their current priority.

3. The Placement Learning Agreement and Mid Point Review meetings should highlight the importance of regular and appropriate supervision and support for students.

4. The PLA and the MPR should also make any relationship issues explicit from the outset as a shared responsibility between students, assessors and tutors - whilst acknowledging differences and the power imbalance of placement relationships.

5. The early address and tackling of any emerging difficulties should be seen as crucial to the success and continuation of placements.

6. In order to ensure transparency of assessment, university staff should highlight any concerns regarding a student's apparent lack of commitment to social work, prior to the commencement of placement.

7. Students should be matched as far as is possible to placements which will meet their needs and provide satisfactory learning opportunities.

8. Practice educators may need more support and ongoing training particularly in respect of how to manage difficult or failing placements.

\section{References}

Barlow, C. and Hall, B.L. (2007) What about Feelings? A Study of Emotion and Tension in Social Work Field Education, Social Work Education 26, 4

Baum, N. (2007) Field Supervisors' Feelings and Concerns at the termination of the Supervisory Relationship British Journal of Social Work 37, 6, 1095-1112

Burgess, R., Campbell, V., Phillips, R., and Skinner K. (1998) Managing unsuccessful or uncompleted placements. The Journal of Practice Teaching in Social Work and Health 1, 1, 4-12

73 J. of Practice Teaching \& Learning 10(1) 2010, pp59-74. DOI: 10.1921/ 146066910X570294. @ w\&b 
Burgess, R. Phillips, R. and Skinner, K. (1998) Practice placements that go wrong. Journal of Practice Teaching in Social Work and Health 1, 2, 48-64

Burgess, R. and Phillips, R (2000) On-site supervisors:The unsung partners in the training team? Journal of Practice Teaching in Health and Social Work.2, 3, 28-46

Chapman $\mathrm{M}$ et al (2003) What we bring to practice teaching students about professional use of self. Journal of Teaching in Social Work_23, 3/4, 3-14

DH (2002) Requirements for Social Work Trainingwww.dh.gov.uk/swqualification/ newrequiremnt

Doel, M. et al (2004) An Audit of Models of Practice Learning in the new Social Work Award. Sheffield: Sheffield Hallam University for the Practice Learning Workforce, TOPPS

Gilligan P. (2007) Well Motivated reformists or nascent radicals: How do applicants to the degree in social work see social problems, their origins and solutions? The British Journal of Social Work 37, 4, 735-760

GSCC (2003) Codes of Practice

GSCC (2007) Suitability for Social Work (suitability doc. PDF) (accessed www. gscc.org.uk on 8-4-08)

Henderson K. (2010) Work based supervisors: Tthe neglected partners in practice learning. Social Work Education, 29, 5: 490-507

Kingston University (2007) Declaration of Suitability for Social Work document Kingston University (2007) B.A. in Social Work - Practice Portfolio

Maidment, J. (1999) Providing Social work field education: Attributes for the job. Journal of Practice Teaching in Social Work and Health Care 2, 1, 54-67

Moriarty, J. and Murray, J. (2007) Who wants to be a Social Worker? British Journal of Social Work 37, 4, 715-733

TOPSS UK Partnership (2002) The National Occupational Standards for Social Work

Wilson, G. and McCrystal, P. (2007) Motivations and Career Aspirations of MSW Students in N. Ireland Social Work Education 26, 1, 35-62

74 J. of Practice Teaching \& Learning 10(1) 2010, pp59-74. DOI: 10.1921/ 146066910X570294. @ wE-b 